\title{
Tensile properties of accident-tolerant aluminum-bearing ferritic steels
}

\author{
Ankan Guria and Indrajit Charit ${ }^{1}$ \\ Department of Chemical \& Materials Engineering \\ University of Idaho, Moscow, ID 83844-3024, USA
}

\begin{abstract}
Tensile behavior of Kanthal APMT ${ }^{\mathrm{TM}}$ steel was studied over a temperature range from room temperature to $500{ }^{\circ} \mathrm{C}$ at three strain rates $\left(10^{-4}, 10^{-3}\right.$ and $\left.10^{-2} \mathrm{~s}^{-1}\right)$. Yield strength, ultimate tensile strength and percentage elongation to fracture were evaluated. Serrated plastic flow was observed in a specific temperature/strain rate regime, signifying occurrence of dynamic strain aging (DSA). Characteristic features of DSA such as plateau/peak in yield and tensile strength as a function of temperature, ductility minima and negative strain rate sensitivity were also observed. The activation energy of serrated flow was found to be affected by diffusion of interstitial impurity modified by high concentration of chromium. Microstructural examination and Vickers hardness testing were also performed on Kanthal $\mathrm{APMT}^{\mathrm{TM}}$ steel. Room temperature tensile properties of the $\mathrm{APMT}^{\mathrm{TM}}$ steel are compared with those of Goodfellow FeCralloy ${ }^{\mathrm{TM}}$ steel in the light of operating strengthening mechanisms.
\end{abstract}

Keywords: ferritic steel; accident-tolerant fuel cladding; Kanthal $\mathrm{APMT}^{\mathrm{TM}}$ steel; tensile test; $\mathrm{I}^{2} \mathrm{~S}-\mathrm{LWR}$

${ }^{1}$ Corresponding author (I. Charit): E-mail - icharit@uidaho.edu; Phone - (+1) 208-885-5964;

Fax - (+1) 208-885-7462 


\section{Introduction}

Zirconium based alloys are extensively used as nuclear fuel cladding materials in light water reactors (LWR) because of their low neutron capture cross section for thermal neutrons, heat transfer properties, and other favorable characteristics [1]. Nonetheless, the FukushimaDaiichi incident showed that these alloys are vulnerable to various issues including the risk of explosion due to hydrogen evolution from zirconium-steam reaction under severe accident scenarios such as loss-of-coolant accident (LOCA). To address these issues, enhanced accident tolerant cladding would require improved high temperature mechanical integrity and enhanced high temperature oxidation/corrosion resistance. Advanced aluminum-bearing, high-chromium ferritic steels such as Kanthal $\mathrm{APMT}^{\mathrm{TM}}$ have been proposed as possible nuclear fuel cladding materials since the aluminum oxide scale provides high oxidation resistance at elevated temperatures [2-4]. $\mathrm{APMT}^{\mathrm{TM}}$ is an advanced powder metallurgical, dispersion strengthened iron based alloy manufactured by Sandvik Inc. and is generally used as high temperature heating elements up to $1250{ }^{\circ} \mathrm{C}$ under a variety of environments. At elevated temperatures and oxidizing atmospheres, this advanced clad steel develops a dense, non-volatile, thermodynamically stable and adherent oxide $\left(\alpha-\mathrm{Al}_{2} \mathrm{O}_{3}\right)$ layer. The combination of excellent oxidation properties and high temperature strength makes the steel unique for high temperature applications [5].

The reported tensile data of APMT steel corresponding to the aforementioned alloy are generally available at temperatures above $800{ }^{\circ} \mathrm{C}$ [6]. During normal operation, the cladding temperature in the Integral Inherently Safe Light Water Reactor $\left(\mathrm{I}^{2} \mathrm{~S}-\mathrm{LWR}\right)$ core is expected to be in the $320-420^{\circ} \mathrm{C}$ temperature range. Because of the key role played by cladding mechanical properties in the fuel rod structural integrity analysis, it is therefore important to obtain mechanical test data of these steels under this temperature range. In this study, the focus was kept on evaluating tensile properties of $\mathrm{APMT}^{\mathrm{TM}}$ steel at varying temperatures (room temperature to $500{ }^{\circ} \mathrm{C}$ ) and strain rates. This work is expected to lead to the development of correlations between microstructure and mechanical properties of $\mathrm{APMT}^{\mathrm{TM}}$ steel. This is relevant because recent studies $[1,4,7]$ on this steel mostly focused on the oxidation/corrosion characteristics of this steel, not on its mechanical properties. 


\section{Materials and Methods}

\subsection{Material}

Two Kanthal APMT ${ }^{\mathrm{TM}}$ steel rods of $12 \mathrm{~mm}$ diameter and $1830 \mathrm{~mm}$ length were procured from Sandvik, Inc. for this study. The rods were received in extruded form and the chemical composition was provided by the manufacturer as Fe-21.5Cr-5.0Al-3.1Mo-0.04C-0.34Si-0.16Mn (in wt.\%). Some minor amounts of $\mathrm{Y}, \mathrm{Zr}$ and $\mathrm{Hf}$ are generally found. The $\mathrm{APMT}^{\mathrm{TM}}$ employs a processing method bit different from the mechanically alloyed powder metallurgy alloys. Instead of mechanical alloying of powder, rapidly solidified powders made by gas atomization are used to produce $\mathrm{APMT}^{\mathrm{TM}}$ products followed by capsule filling, hot isostatic pressing, machining of billets and hot extrusion [6]. Exact details of the process parameters are not available due to their proprietary nature. For comparison, a FeCralloy ${ }^{\mathrm{TM}}$ steel rod (nominal composition of Fe-22Cr5Al-0.1Y-0.1Zr along with minor amounts of $\mathrm{C}, \mathrm{Si}, \mathrm{Mn}$ etc. present) of $16 \mathrm{~mm}$ diameter was procured from Goodfellow Inc. and used for tensile testing for this study. This alloy was fabricated by conventional powder metallurgy route. However, it may be noted that precise comparison between the two materials in the current form is not possible because of the lack of adequate processing details of the two materials.

\subsection{Microscopic sample preparation}

Samples from axial and vertical directions of a small section of $\mathrm{APMT}^{\mathrm{TM}}$ steel rod were sectioned and subsequently prepared following standard metallographic procedures. The samples were first hot mounted in Bakelite. After grinding and polishing, aqua regia (a mixture of hydrochloric acid and nitric acid in 3:1 ratio by volume) was used to perform etching on the metallographic samples to reveal the microstructure. The etched samples were then examined with an Olympus PMG-3 light microscope.

A thin sample disk was sectioned by using a diamond saw and mechanically thinned by grinding and polishing to about $50 \mu \mathrm{m}$ thickness. Next, disks of $3 \mathrm{~mm}$ diameter were punched out of the foil using a Gatan mechanical punch. A few disks were electro-jet polished using a Fischione twin jet polisher. The electrolyte used was a mixture of methanol and nitric acid (80:20 ratio by volume) and the voltage used was about $30 \mathrm{~V}$. The jetpolished specimens were examined in a JEOL 2010J transmission electron microscope (TEM) operated at an accelerating voltage of $200 \mathrm{kV}$. 


\subsection{Mechanical Testing}

Microhardness tests were performed on the as-polished samples using a Leco LM-100 microhardness tester fitted with a Vickers indenter along two directions (axial and transverse). Tensile specimens of $25.4 \mathrm{~mm}$ gauge length and about $6.3 \mathrm{~mm}$ gauge diameter were machined keeping the specimen gauge section along the extrusion direction. The specimens were subjected to uniaxial tensile tests in an Instron 5982 tester in the temperature range of 25 to $500{ }^{\circ} \mathrm{C}$ and at nominal strain rates of $10^{-4}, 10^{-3}$ and $10^{-2} \mathrm{~s}^{-1}$. At first tensile tests were carried out at strain rates of $10^{-4}$ and $10^{-3} \mathrm{~s}^{-1}$ to form a preliminary map of temperature and strain rate combination where serrated flow was observed. Following that, the temperatures for carrying out tensile tests at $10^{-2}$ $\mathrm{s}^{-1}$ were determined. Since our primary objective of this work was to observe mechanical behavior of APMT steel in the temperature range of $320-420{ }^{\circ} \mathrm{C}$ and understand the serrated flow region, further tests were not conducted beyond this range for the strain rate of $10^{-2} \mathrm{~s}^{-1}$. During each elevated temperature test, the temperature was controlled within $\pm 2{ }^{\circ} \mathrm{C}$.

\section{Results and discussion}

\subsection{Microstructural characterization}

Figures 1a and b show optical micrographs of the as-received $\mathrm{APMT}^{\mathrm{TM}}$ steel specimen along the axial and vertical directions, respectively, as observed by optical microscopy. The microstructures were taken from the center region of the mounted specimen. While the microstructure perpendicular to the axial direction was revealed as equiaxed grains only, the surface in the vertical direction exhibited a mixture of some equiaxed grains with mostly elongated grains. However, the average grain size of the microstructure was found to be $10 \pm 2 \mu \mathrm{m}$.

Figure 1c shows a TEM image of the APMT alloy (taken from the axial direction) microstructure of the alloy in detail. The TEM structure reveals much finer grain structure (1-3 $\mu \mathrm{m}$ ) which could not be revealed in the optical micrographs. Furthermore, dislocations were found to be present in these boundaries. That is why it is thought that the grain structure is basically composed by fine subgrains. Electron-back-scatter-diffraction (EBSD) studies are currently being performed, shedding more light on this aspect. Two types of precipitates were observed. The smaller ones $(40-65 \mathrm{~nm})$ were found to be present in the (sub)grain interior and the larger particles $(100-400 \mathrm{~nm})$ were mostly on the grain boundaries. Jönsson et al. [6] 
commented that in $\mathrm{APMT}^{\mathrm{TM}}$ steel the dispersed second phase particles typically consist of oxides, carbides and nitrides, which appear to be resistant to coarsening even after long-term exposure at elevated temperatures. However, in the current study no such elevated temperature experiments were performed to study the thermal stability of the dispersed particles. Nonetheless, no particle coarsening was observed in the tensile tested specimens at 300 and 500 ${ }^{\circ} \mathrm{C}$ as revealed by preliminary TEM observation.
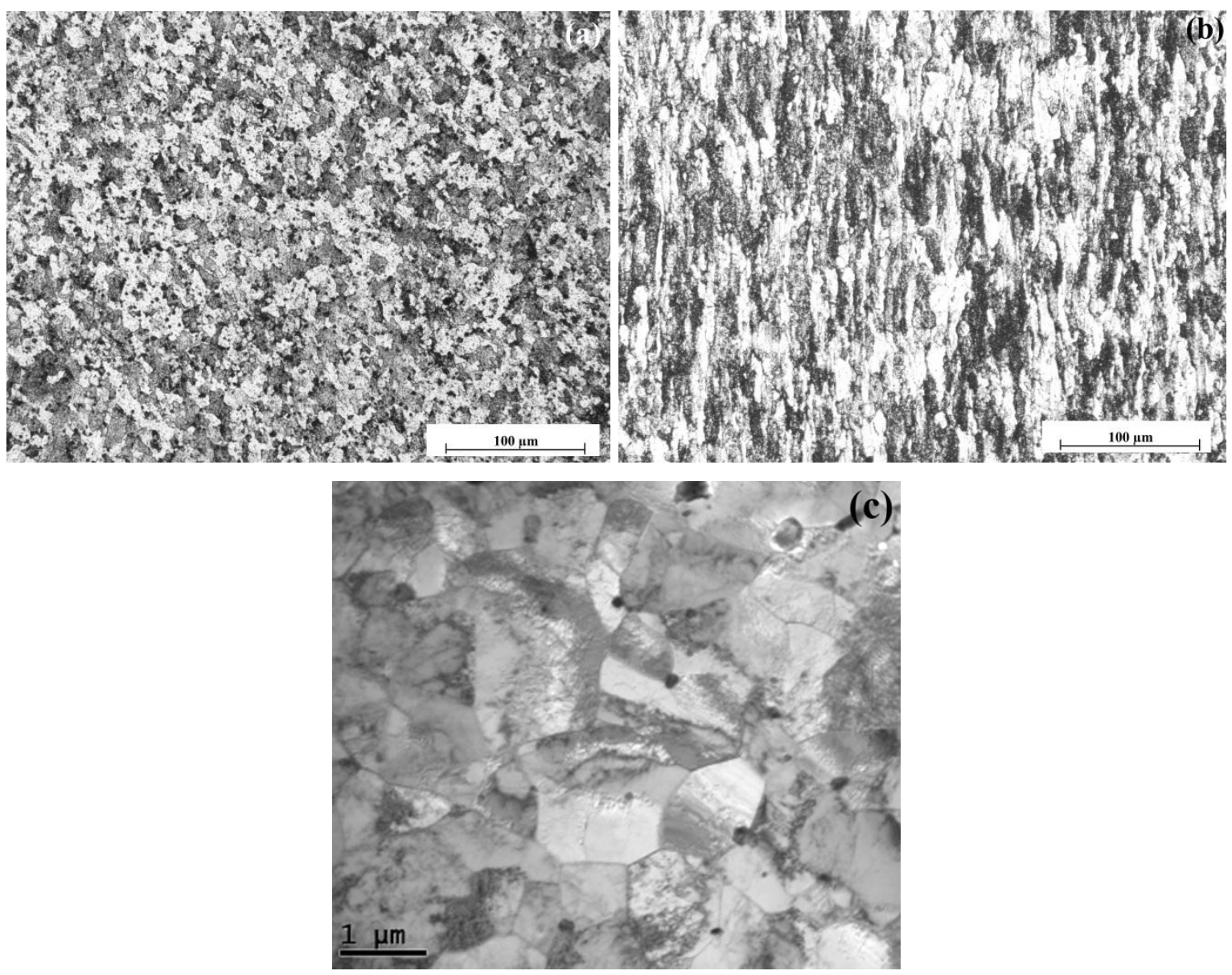

Figure 1. Optical micrographs of $\mathrm{APMT}^{\mathrm{TM}}$ steel rod surface normal to (a) the axial direction and (b) transverse direction. c) A TEM bright field image of the as received APMT $^{\mathrm{TM}}$ alloy showing fine (sub) grain structure and second phase particles.

\subsection{Mechanical properties}

Vickers microhardness testing of the APMT rod was performed both along the axial and vertical directions yielding hardness values along the axial direction and vertical to be $307 \pm 7$ and $316 \pm 5$, respectively. Thus, it can be suggested that no significant mechanical anisotropy in hardness was found to be present between the two directions of the extruded rod. 
Tensile properties (yield strength, ultimate tensile strength and percentage elongation to fracture), of $\mathrm{APMT}^{\mathrm{TM}}$ steel tested under different temperatures and strain rates were evaluated. Room temperature tensile properties were evaluated at the strain rate of $10^{-3} \mathrm{~s}^{-1}$. Yield strength was $682 \mathrm{MPa}$, ultimate tensile strength $750 \mathrm{MPa}$ and elongation to fracture $26 \%$. Figure 2 shows some representative engineering stress-strain curves of $\mathrm{APMT}^{\mathrm{TM}}$ steel deformed at $10^{-4} \mathrm{~s}^{-1}$ at different temperatures (from room temperature to $500{ }^{\circ} \mathrm{C}$ ). At room temperature, the stress-strain curve was smooth. However, serrations were observed in the intermediate temperature range of $225-3500^{\circ} \mathrm{C}$ at $10^{-4} \mathrm{~s}^{-1}$ as shown in Figure 2. At $500{ }^{\circ} \mathrm{C}$ no serration was observed.

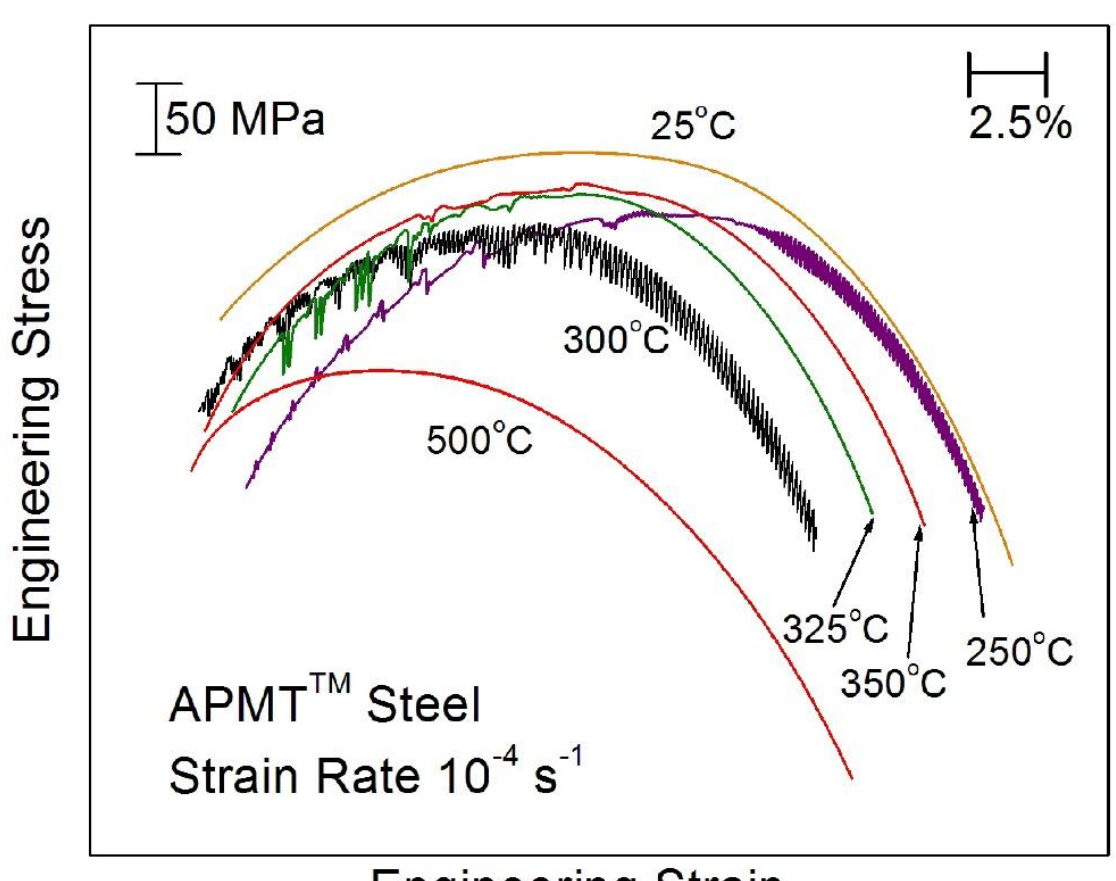

Figure 2. Engineering stress strain curves of $A P M T^{\mathrm{TM}}$ steel at $10^{-4} \mathrm{~s}^{-1}$ for different temperatures. Note that in order to show the serrations clearly the curve for $250{ }^{\circ} \mathrm{C}$ curve is slightly shifted to the right.

Two specimens were tested for some temperatures and strain rates, the error being within $\pm 10-20 \mathrm{MPa}$. Due to a large number of test conditions and limited material stock, tests could not be replicated for all the conditions. The variations of $0.2 \%$ offset yield strength (YS) and ultimate tensile strength (UTS) with temperature for different strain rates $\left(10^{-4}, 10^{-3}\right.$ and $\left.10^{-2} \mathrm{~s}^{-1}\right)$ are shown in Figures $3 \mathrm{a}$ and $\mathrm{b}$, respectively. As shown in those figures, the plot at $10^{-2} \mathrm{~s}^{-1}$ showed a plateau, that at $10^{-3} \mathrm{~s}^{-1}$ showed a peak and a plateau, and the curve at $10^{-4} \mathrm{~s}^{-1}$ showed a 
plateau. Figure $3 \mathrm{c}$ shows the variation of elongation to fracture with temperature for different strain rates $\left(10^{-4}, 10^{-3}\right.$ and $\left.10^{-2} \mathrm{~s}^{-1}\right)$. Ductility variation is not very uniform in this steel. However, there were minima observed in the temperature range of serrated flow at all strain rates. It is important to note that all elongation to fracture values were consistently $>20 \%$ even in the DSA regime. Tensile tests at higher temperatures were not carried out since the application for this steel does not call for temperatures beyond $420{ }^{\circ} \mathrm{C}$ under normal LWR operating conditions. Figure $3 \mathrm{~d}$ shows the variation of uniform plastic elongation against temperature. It can be observed from the plot that within the DSA regime actually the contribution of the uniform elongation increased.

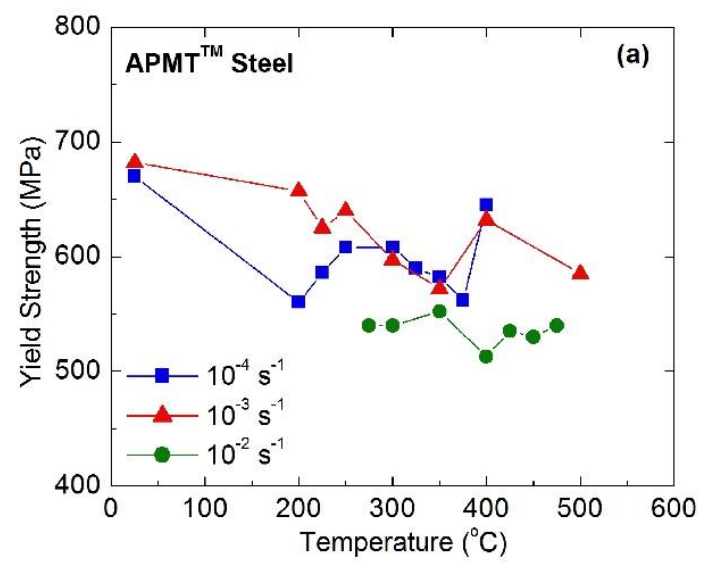



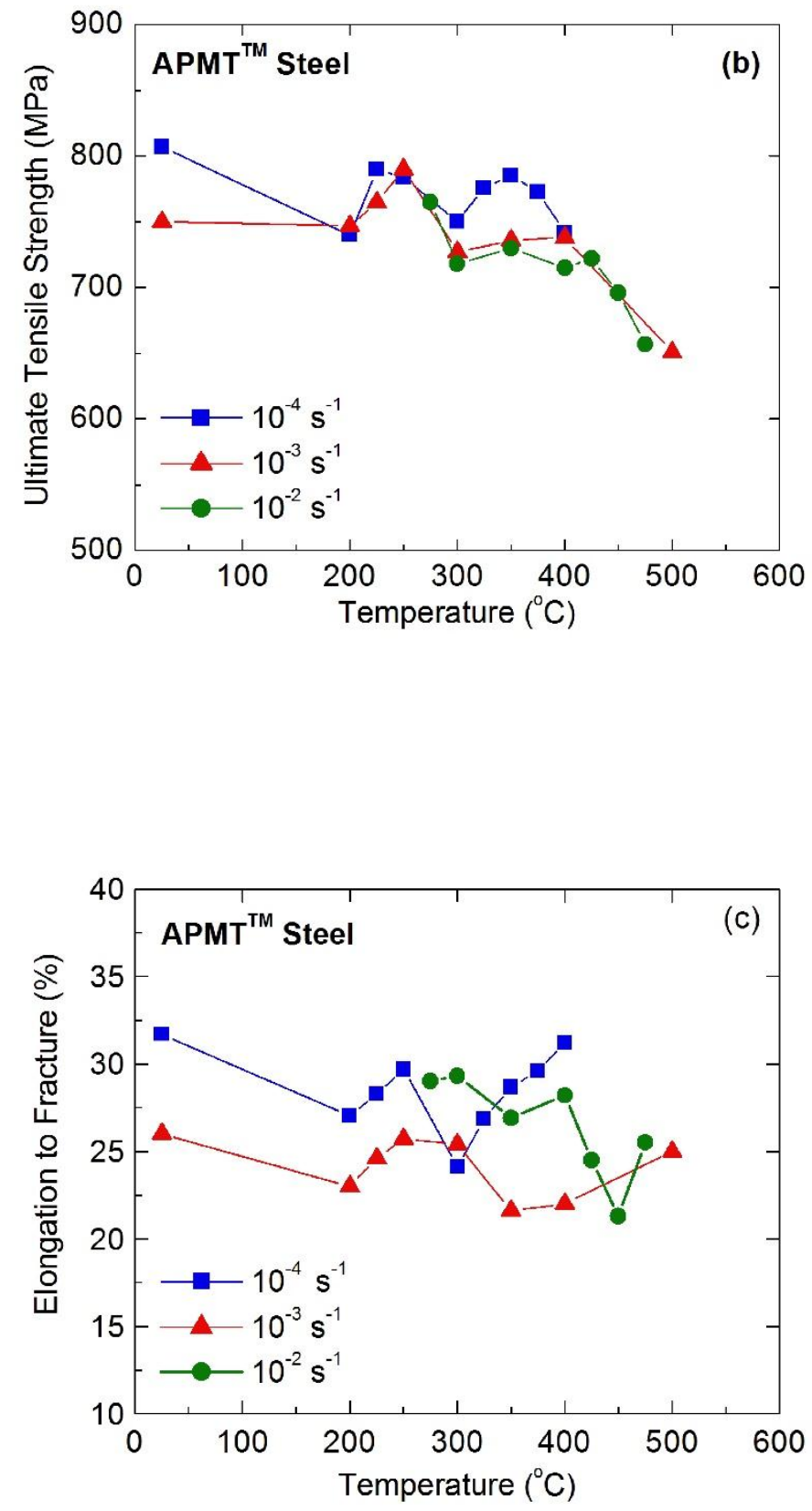


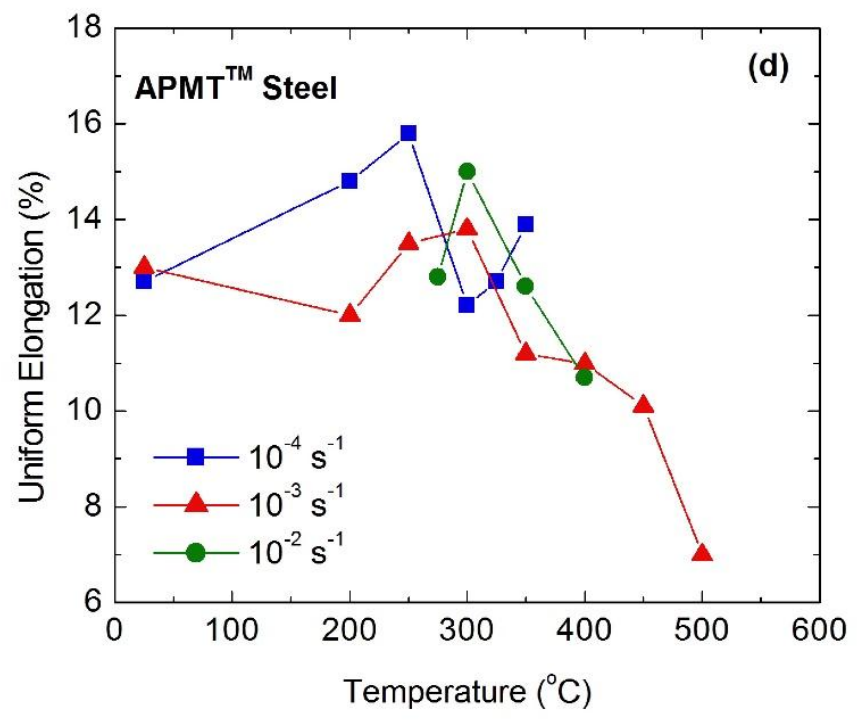

Figure 3. The variations of (a) yield strength, (b) ultimate tensile strength, (c) elongation to fracture, (d) percent uniform elongation of $\mathrm{APMT}^{\mathrm{TM}}$ steel as a function of temperature.

Generally, strain rate sensitivity $(m)$ is calculated from the following equation:

$\sigma=C \dot{\varepsilon}^{m}$

where $\sigma$ is flow stress, $\dot{\varepsilon}$ true strain rate, and $C$ a constant. Interestingly, DSA phenomenon is associated with negative strain rate sensitivity. Under normal conditions, the flow stress increases (or decreases) as the strain rate increases (or decreases). That is why $m$ values obtained are positive under most conditions. That means resistance to dislocation motion increases as the strain rate is increased and vice versa. However, the opposite is true under DSA. Here the resistance to dislocation movement increases as the strain rate is decreased and vice versa. This is because slower moving dislocations (low strain rate or dislocation velocity) spend longer time in arrest mode at the obstacles, thus providing more time for solutes to diffuse to those dislocations. Solutes develop atmospheres around those dislocation cores and increase flow stress [8]. That is why negative $m$ values are obtained. Figure 4 shows $m$ values of the APMT ${ }^{\mathrm{TM}}$ steel at three temperatures $\left(300,350\right.$ and $\left.400{ }^{\circ} \mathrm{C}\right)$, which coincide with the DSA regime. The flow stress used in the calculation of $\mathrm{m}$ was based on the true stress corresponding to yield stress. The negative $m$ values corroborates occurrence of DSA in APMT ${ }^{\mathrm{TM}}$. The fall in ductility in the region of DSA was essentially due to pronounced and rapid drop in necking strain which overplays even the slight increase in uniform strain as found in Figures 3c-d. The rapid drop in 
necking strain was due to fall in strain rate sensitivity in the region of DSA [9]. Negative strain rate sensitivity is known to promote flow localization which enhances the probability of failure at such sites and thereby reducing the ductility.

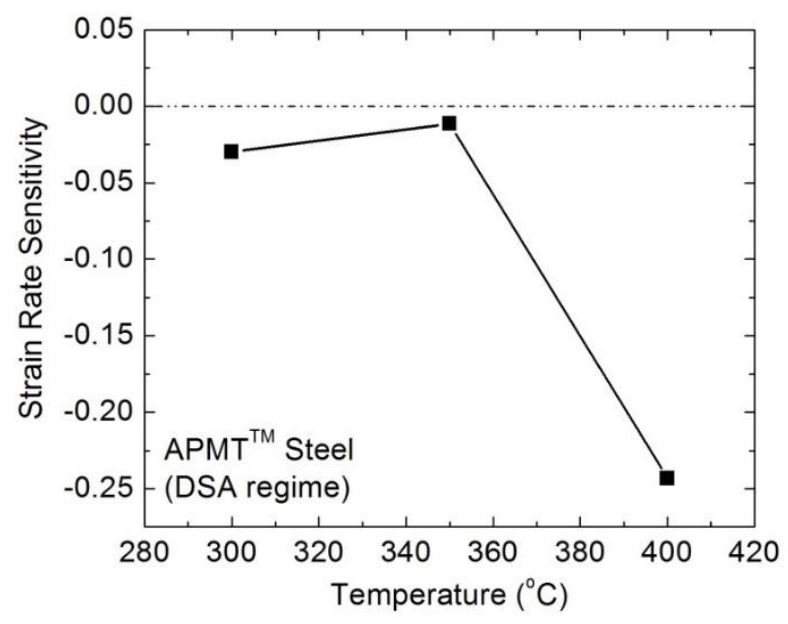

Figure 4. Variation of strain rate sensitivity of APMT steel with temperature under the DSA regime. Note the strain rate sensitivity values are negative.

Figure 5 depicts the strain rate as a function of inverse temperatures for all the elevated temperature tensile tests. The 'open square' symbol represents tests that exhibited no serrated flow while the 'filled square' symbol represents tests that did show serrated flow. Following the filled symbols, the DSA domain can be configured. One can calculate activation energy for the onset and disappearance of serrated flow (DSA). The activation energy was calculated according to the method proposed by Jenkins and Smith [10]. The activation energy $(Q)$ was determined using the following equation:

$\dot{\varepsilon}=\operatorname{Aexp}\left(-\frac{Q}{R T}\right)$

where $T$ is the temperature in $\mathrm{K}, R$ is the universal gas constant, $A$ is a constant, and $\dot{\varepsilon}$ has the already defined meaning. The activation energy for the onset of serrations is found to be $142 \pm 21$ $\mathrm{kJ} / \mathrm{mol}$ whereas for disappearance of the serrated flow is calculated to be $212 \pm 45 \mathrm{~kJ} / \mathrm{mol}$. Decrease in strain rate facilitates diffusion of solutes to the dislocations; thus serrations arise at a lower temperature [11]. Both high temperature and low strain rate result in a larger size of solute atmosphere around the dislocations, causing their arrest in the slip path. This explains the typical configuration of Figure 5, where onset and disappearance of serrations occur at lower temperatures with the decrease of strain rates during tensile deformation. 


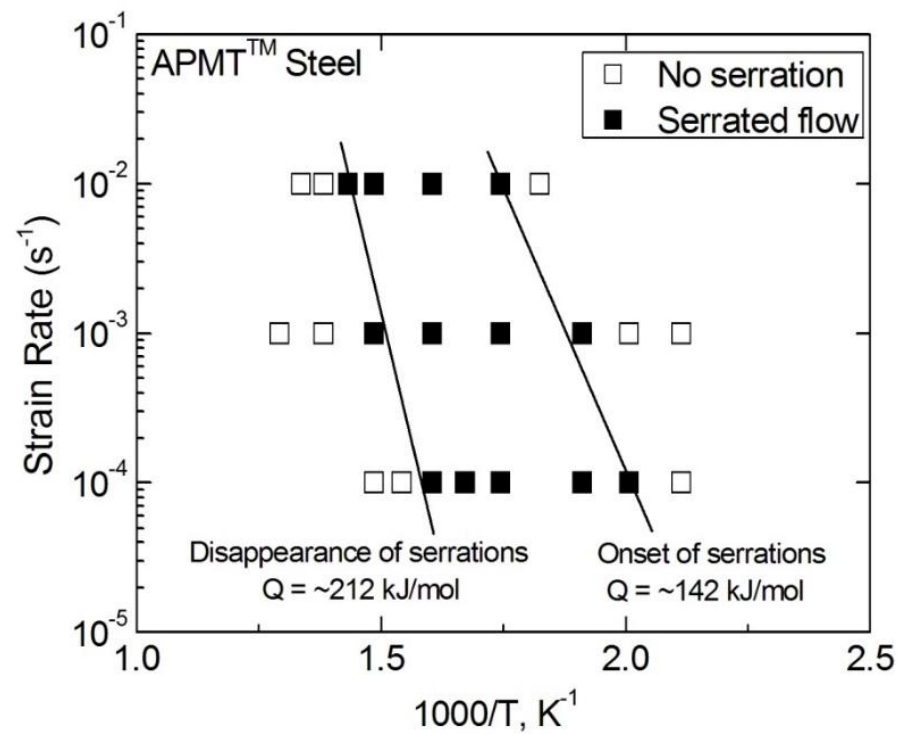

Figure 5. The strain-rate versus inverse temperature plot demarcating the DSA regime with onset of serrations and disappearance of serrations.

Generally, the onset of serrations associated with DSA in low carbon steel and Cr-bearing ferritic-martensitic steels is attributed to interactions between mobile dislocations and carbon and/or nitrogen interstitial impurities, leading to repeated locking and unlocking of dislocations by the interstitial solute atmospheres. To the best of our knowledge, there is no other study which exclusively investigated the DSA effect in Fe-Cr-Al based steels with high concentration of solutes. Tjong and Zhu [12] investigated the effect of DSA on the creep behavior of a Fe-24Cr4Al alloy. However, there was no detailed evaluation of deformation kinetics in the serrated flow regime. The present study obtained about $142 \mathrm{~kJ} / \mathrm{mol}$ activation energy. It is generally accepted that the activation energy values of nitrogen and carbon interstitial atoms in $\alpha$-Fe are $\sim 76$ and $\sim 78 \mathrm{~kJ} / \mathrm{mol}$, respectively $[13,14]$. Purely interstitial diffusion cannot lead to such high activation energy $(142 \mathrm{~kJ} / \mathrm{mol})$. Even though the activation energy of carbon diffusion through $\gamma$-Fe (FCC) is $\sim 137 \mathrm{~kJ} / \mathrm{mol}$ [15] being apparently close to $142 \mathrm{~kJ} / \mathrm{mol}$, the $\mathrm{APMT}^{\mathrm{TM}}$ alloy does not contain any austenite. Presence of $\mathrm{Cr}(21.5 \%), \mathrm{Al}(5 \%)$ and Mo (3\%), all ferrite-stabilizing elements [16], renders the steel fully ferritic (BCC crystal structure). Thus, carbon diffusion through austenitic phase (FCC) cannot be the mechanism responsible. The most plausible scenario is the modification of the mobility of carbon solutes because of the presence of high concentration of substitutional solutes, especially chromium. However, when the temperature becomes high enough, the importance of interstitial solute atoms becomes less important and gradually shifts to 
substitutional solute diffusion through the iron lattice leading to the disappearance of serrated flow. In this study, an activation energy of $\sim 212 \mathrm{~kJ} / \mathrm{mol}$ was obtained for disappearance of serrated flow. This activation energy is found to be lower than the activation energy of lattice self-diffusion in $\alpha$-Fe or activation energy of chromium diffusion in dilute Fe-Cr alloys, which are quite similar ( 250 kJ/mol) [17]. However, some detailed work on chromium diffusion in iron demonstrated that the activation energy of chromium diffusion in iron lattice is gets reduced in concentrated Fe-Cr alloys (such as $\sim 202 \mathrm{~kJ} / \mathrm{mol} \mathrm{Fe}-25 \mathrm{Cr}[18]$ and $\sim 212 \mathrm{~kJ} / \mathrm{mol}$ in Fe-19Cr [19]). Thus, the activation energy for disappearance of serrations can be explained. However, this issue needs further in-depth investigation.

\subsection{Comparison of APMT ${ }^{T M}$ tensile properties with FeCralloy}

Tensile properties of $\mathrm{APMT}^{\mathrm{TM}}$ steel are compared with those of FeCralloy rod measured under similar test conditions, as shown in Table 1. At room temperature, the $\mathrm{APMT}^{\mathrm{TM}}$ steel has a higher yield strength (by 70.5\%) and ultimate tensile strength (by 23.5\%) but less elongation to fracture compared to FeCralloy.

Table 1. A summary of tensile properties of APMT ${ }^{\mathrm{TM}}$ and FeCralloy (strain rate of $10^{-3} \mathrm{~s}^{-1}$ )

\begin{tabular}{|l|c|c|c|c|}
\hline Material (Rod) & $\begin{array}{c}\text { Test } \\
\text { Temperature } \\
\left({ }^{\circ} \mathbf{C}\right)\end{array}$ & $\begin{array}{c}\text { Yield Strength } \\
(\mathbf{M P a})\end{array}$ & $\begin{array}{c}\text { Ultimate Tensile } \\
\text { Strength (MPa) }\end{array}$ & $\begin{array}{c}\text { Elongation to } \\
\text { Fracture (\%) }\end{array}$ \\
\hline Kanthal APMT $^{\mathrm{TM}}$ & 25 & 682 & 750 & 26.0 \\
\hline & 300 & 597 & 727 & 25.4 \\
\hline Goodfellow FeCralloy & 25 & 400 & 583 & 34.0 \\
\hline & 300 & 251 & 539 & 36.0 \\
\hline
\end{tabular}

As no microstructural characteristics of FeCralloy have been reported in previous sections, here some results are included. Figure 6a shows an optical micrograph of the as received FeCralloy specimen. The grain size of FeCralloy as measured by the mean linear intercept technique varied between $25 \mu \mathrm{m}$ to $34 \mu \mathrm{m}$, which is much larger than that of $\mathrm{APMT}^{\mathrm{TM}}$ alloy. TEM study as shown in Figure $6 \mathrm{~b}$ revealed no presence of subgrains. It revealed a microstructure containing some small particles $(21 \pm 7 \mathrm{~nm})$ mainly inside the grains along with some larger second phase particles (500 $\mathrm{nm}$ to $1 \mu \mathrm{m}$ in length) at or near the grain boundaries. Although the tensile testing matrix was not as extensive as that of $\mathrm{APMT}^{\mathrm{TM}}$, FeCralloy did 
exhibit serrated flow in the intermediate temperature range as shown in the engineering stressstrain curves.
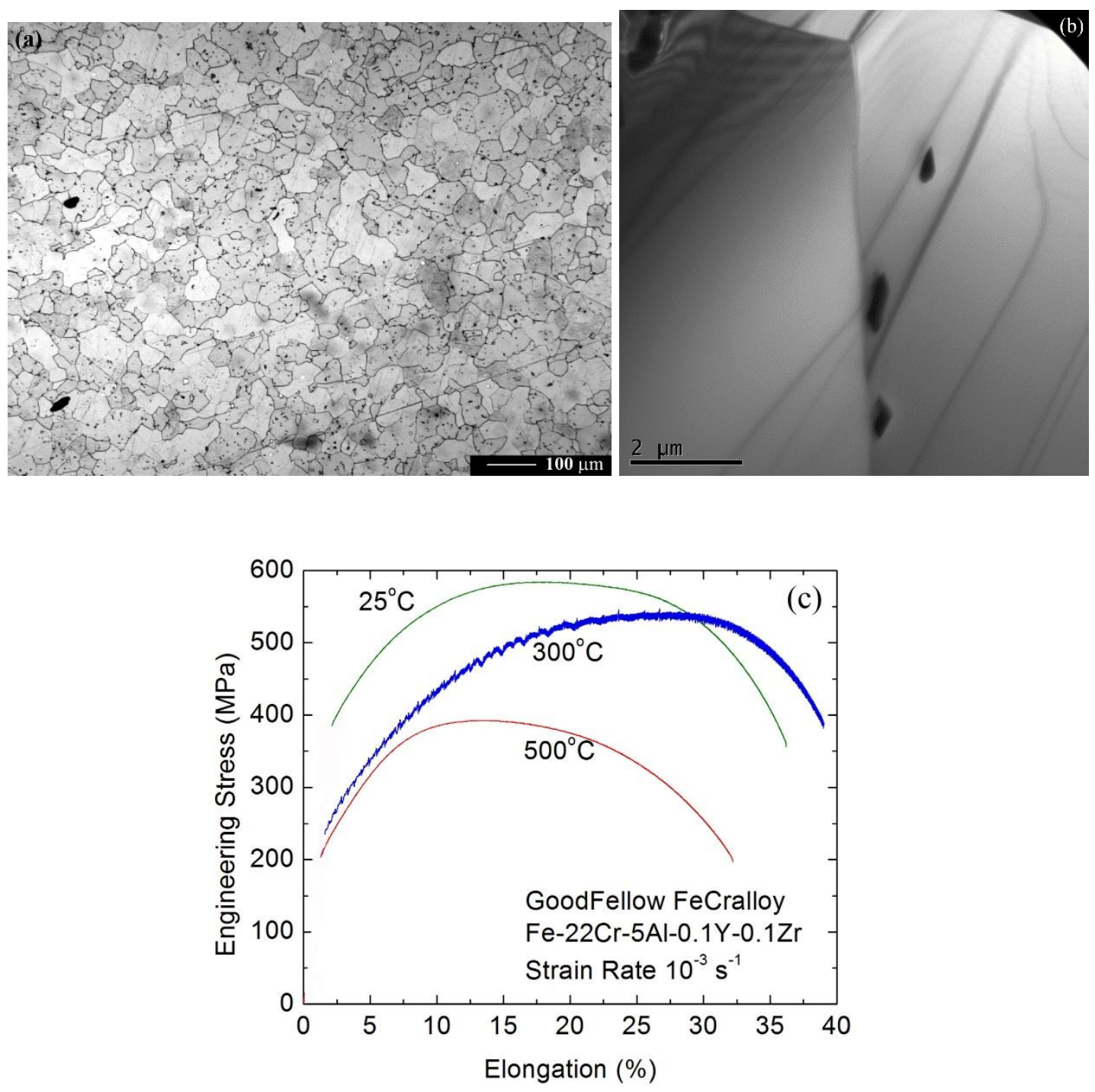

The key to understanding the higher yield strength of $\mathrm{APMT}^{\mathrm{TM}}$ compared to FeCralloy is through various strengthening mechanisms that may affect the total strength. Four main strengthening mechanisms can be operative in $\mathrm{APMT}^{\mathrm{TM}}$ alloy: (1) precipitation strengthening from various type of particles, (2) grain boundary strengthening due to grain refinement (Hall- 
Petch relationship) and/or subgrain strengthening, (3) solid solution strengthening, and (4) dislocations strengthening [20]. One widely used approach is expressing the yield strength $\left(\sigma_{y}\right)$ in terms of linear summation of all the strengthening components:

$$
\sigma_{y}=\sigma_{o}+\sigma_{s s}+\sigma_{d}+\sigma_{b}+\sigma_{p}
$$

where $\sigma_{o}$ is the lattice friction stress representing the overall resistance of the crystal lattice to dislocation movement, $\sigma_{s s}$ is the solid solution strengthening, $\sigma_{b}$ is boundary strengthening \{either grain size strengthening $\left(\sigma_{g s}\right)$, or subgrain strengthening $\left.\left(\sigma_{s}\right)\right\}$, and $\sigma_{p}$ is the particle strengthening. From Table 1, the difference between the yield strength of $\mathrm{APMT}^{\mathrm{TM}}$ and FeCralloy $^{\mathrm{TM}}$ at room temperature is $282 \mathrm{MPa}$. Without calculating contributions of all the strengthening mechanisms, here we focus on rationalizing the difference from two aspects: composition and subgrain structure. Thus, we utilize the concepts of two strengthening mechanisms, solid solution strengthening and sub-grain strengthening, respectively.. APMT ${ }^{\mathrm{TM}}$ steel is largely similar in composition with FeCralloy with the exception of molybdenum content (3 wt.\%). Each wt.\% of Mo in ferrite solid solution may impart about $57.3 \mathrm{MPa}$ [21]. Note that there is no Mo in FeCralloy even though other elements are present in $\mathrm{APMT}^{\mathrm{TM}}$ and FeCralloy ${ }^{\mathrm{TM}}$ almost to the same amount. Thus, if all Mo in $\mathrm{APMT}^{\mathrm{TM}}$ steel remains in solid solution, it alone can add about $170 \mathrm{MPa}$ to the yield strength via the solid solution strengthening mechanism.

Grain size strengthening, also known as the Hall-Petch strengthening, contributes to the yield strength as it varies with grain size $\left(d_{g}\right)$ as shown in the following equation:

$\sigma_{g s}=k_{y} d_{g}^{-0.5}$,

where $k_{y}$ is a material-specific constant. On the other hand, substructure strengthening generally varies inversely with subgrain size $\left(d_{s}\right)$

$\sigma_{s}=B d_{s}^{-1}$

where $B$ is a constant which depends on microstructural factors. The constant $B$ represents the strength of subgrain boundary as a barrier to slip. The value of $B$ is obtained as about 195

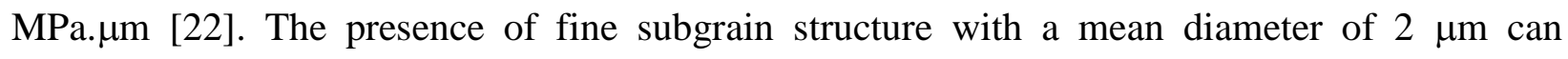
contribute to the tune of about $98 \mathrm{MPa}$. Hence, solid solution strengthening (due to the presence of Mo) and subgrain strengthening in $\mathrm{APMT}^{\mathrm{TM}}$ steel can contribute up to $(170+98) \mathrm{MPa}$ or 268 $\mathrm{MPa}$. Experimentally we noted that there is $282 \mathrm{MPa}$ difference between the yield strength. Of course, contributions from other solid solution strengtheners $(\mathrm{Cr}, \mathrm{Al}, \mathrm{C})$, strengthening from dispersed particles and dislocations strengthening will contribute to the rest of the strength in 
both alloys. The non-availability of processing details of both materials makes precise calculations of strengthening contributions not plausible.

At $300{ }^{\circ} \mathrm{C}$, the yield strength and ultimate tensile strength of APMT steel were about $137 \%$ and $34.5 \%$ more than those of FeCralloy whereas the elongation to fracture in $\mathrm{APMT}^{\mathrm{TM}}$ was about $30 \%$ less compared to FeCralloy. Some of the strengthening mechanisms get weaker at higher temperatures but not all in the same way. At this point, no attempt has been made to elucidate those effects due to the lack of detailed fundamental information.

There are many other characteristics of $\mathrm{APMT}^{\mathrm{TM}}$ steel that could not discussed in this work but must be taken into account to assess the viability of $\mathrm{APMT}^{\mathrm{TM}}$ alloy as a fuel cladding material in the $\mathrm{I}^{2} \mathrm{~S}-\mathrm{LWR}$ design. The effect of thermal aging embrittlement and irradiation performance are some of the issues that need to be addressed. Furthermore, the steel is not produced in the optimized form needed for its use as the nuclear fuel cladding material. Under the aegis of the DOE Accident-Tolerant Fuel program, the Oak Ridge National Laboratory has been engaged in developing various compositions of aluminum-bearing ferritic steels [23]. More mechanical properties results from those efforts should become available in the open literature over the upcoming years.

\section{Conclusions}

$\mathrm{APMT}^{\mathrm{TM}}$ steel received in the rod form shows quite high yield strength of $>500 \mathrm{MPa}$ at all temperatures and strain rates. The ultimate tensile strength was found to be $>650 \mathrm{MPa}$ at all temperatures. The trend in ductility was not uniform but remained above $20 \%$ (elongation to fracture) under all conditions of testing. Serrations are observed in the stress-strain curves at the intermediate temperatures in certain strain rate ranges due to dynamic strain aging. The solid solution strengthening imparted by Mo and subgrain strengthening account for the higher yield strength of Kanthal APMT ${ }^{\mathrm{TM}}$ steel than that of Goodfellow FeCralloy ${ }^{\mathrm{TM}}$. More detailed analyses of other properties are needed to fully assess APMT ${ }^{\mathrm{TM}}$ for $\mathrm{I}^{2} \mathrm{~S}-\mathrm{LWR}$ fuel cladding applications.

\section{Acknowledgments}

The research was performed using funds received from the DOE Office of Nuclear Energy's Nuclear Energy University Programs (NEUP). We would also like to acknowledge Professor Bojan Petrovic at Georgia Institute of Technology for leading the $\mathrm{I}^{2} \mathrm{~S}-\mathrm{LWR}$ program and Dr. 
Paolo Ferroni at Westinghouse for facilitating Materials Working Group's work. We would like to acknowledge the assistance provided by Drs. T. Williams and S. Pasebani for assistance with the TEM work.

\section{References}

1. Murty, K.L., Charit, I., 2008. Structural materials for Gen-IV reactors: Challenges and opportunities. J. Nucl. Mater. 383, 189-195.

2. Zinkle, S.J., Terrani, K.A., Gehin, J.C., Ott, L.J., Snead, L.L., 2014. Accident tolerant fuels for LWRs. J. Nuc. Mater. 448, 374-379.

3. Terrani, K.A., Zinkle, S.J., Snead, L.L., 2014. Advanced oxidation-resistant iron-based alloys for LWR fuel cladding. J. Nucl. Mater. 448, 420-435.

4. Pint, B.A., Terrani, K.A., Brady, M.P., Cheng, T., Keiser, J.R., 2013. High temperature oxidation of fuel cladding candidate materials in steam-hydrogen environments. J. Nucl. Mater. 440 (2013) 420427.

5. Jönsson, B., Berglund, R., Magnusson, J., Henning, P., Hättestrund, M., 2004. High temperature properties of a new powder metallurgical FeCrAl alloy, Mater. Sci. Forum 461-464, 455-462.

6. Petrovic, B., 2014. The integral inherently safe light water reactor, Nucl. Eng. Inter. March (2014) 2629.

7. Hellström, K., Israelsson, N., Mortazavi, N., Canovic, S., Halvarsson, M., Svensson, J.-E., Johansson, L.-G. 2015. Oxidation of a dispersion strengthened powder metallurgical FeCrAl alloy in the presence of $\mathrm{O}_{2}$ at $1100{ }^{\circ} \mathrm{C}$. Oxid. Met. 83, 533-558.

8. Cunningham S., 1999. Effect of substitutional elements on dynamic strain aging (MS thesis). McGill University, Montreal, Canada.

9. G.E. Dieter, 2001. Mechanical Metallurgy, McGrawHill Publishers, New York.

10. Jenkins, C.F., Smith, G.V., 1969. Serrated plastic flow in austenitic stainless steel. Trans. Metall. Soc. AIME 245, 2149-2156.

11. Rodriguez, P., 1984. Serrated plastic flow. Bull. Mater. Sci. 6, 653-63.

12. Tjong, S.C., Zhu, S.M., 1997. Creep and low-cycle fatigue behavior of ferritic Fe-24Cr-4Al alloy in the dynamic strain aging regime: Effect of aluminum addition. Metall. Mater. Trans. 28A, 1347-1355.

13. Stanley, J., 1949. The diffusion and solubility of carbon in alpha iron. Trans. AIME 185, 752-760.

14. Kucera, J., Stransky, K., 1982. Diffusion in iron, iron solid solution and steels. Mater. Sci. Eng. 52, 138.

15. Callister, W.D., Rethwisch, D.G., 2010. Materials Science \& Engineering: An Introduction (ed. 8). John Wiley \& Sons, USA, 2010.

16. Honeycombe, R.W.K., 1981. Steels: Microstructure and Properties. Edward Arnold, London.

17. Brandes, E.A., Brook, G.B., 1998. Smithells Metals Reference Book, Butterworth-Heinemann, Oxford, UK.

18. Paxton, H.W., Kunitake, H.W., 1960. Diffusion in the iron-chromium System. Trans. Metall. Soc. AIME 218, 1003-1009.

19. Bowen, A.W., Leak, G.M., 1970. Diffusion in BCC iron base alloys. Metall. Trans. 1, 2767-2773.

20. Song, R., Ponge, D., Raabe, D., 2005. Improvement in work hardening rate of ultrafine grained steels through second phase particles. Scripta Mater. 52, 1075-1080.

21. Totten, G.E., Xie, L., Funatani, K, Handbook of Mechanical Alloy Design. CRC Press, New York, 2003.

22. C.M. Young and O.D. Sherby, J. Iron and Steel Inst., 211 (1973) 640-647.

23. Yamamoto, Y., Yang, Y., Field, K.G., Terrani, K., Pint, B.A., Snead, L.L., 2014. Letter Report Documenting Progress of Second Generation ATF FeCrAl Alloy Fabrication. ORNL/LTR-2014/219. 